Research Article

\title{
Influence of the Skid Resistance of Ultrathin Wearing Course with Various Types of Asphalt Binders
}

\author{
Hongfu Liu $\mathbb{D}^{1,2}{ }^{1,2}$ Teng Guo, ${ }^{2}$ Chenxi Yang, ${ }^{2}$ Yunyong Huang, ${ }^{2}$ and Xuelian $\mathrm{Li}^{2}$ \\ ${ }^{1}$ Key Laboratory of Special Environment Road Engineering of Hunan Province, Changsha University of Science and Technology, \\ Changsha 410114, China \\ ${ }^{2}$ School of Traffic and Transportation Engineering, Changsha University of Science and Technology, Changsha 410114, China
}

Correspondence should be addressed to Hongfu Liu; lhf0625@csust.edu.cn

Received 11 August 2020; Revised 5 September 2020; Accepted 31 October 2020; Published 16 November 2020

Academic Editor: Ivan Giorgio

Copyright (C) 2020 Hongfu Liu et al. This is an open access article distributed under the Creative Commons Attribution License, which permits unrestricted use, distribution, and reproduction in any medium, provided the original work is properly cited.

Ultrathin wearing course (UTWC) has been widely applied in both asphalt pavements preventive maintenance and functional overlay. This study's objective is to evaluate the influence of different modified asphalt binders with warm mix additives on the skid resistance of UTWC and to reveal the attenuation law of skid resistance of UTWC. Three types of modified asphalt binders (Styrene-Butadiene-Styrene- (SBS-) modified asphalt, Acrylester Rubber- (AR-) modified asphalt, and SinoTPS-modified asphalt) and sasobit warm mix asphalt additive were selected to prepare asphalt mixtures. The Model Mobile Load Simulator 3 (MMLS3) was used to simulate repeated vehicle loading and abrasion. The British Pendulum Number (BPN) and Mean Texture Depth (MTD) were chosen to evaluate the skid resistance of the UTWC. The Analysis of Range (ANOR) and Analysis of Variance (ANOVA) were used to verify the significance of asphalt binder on the antiskid performance of the UTWC. ANOR and ANOVA show that the influence of different modified asphalt binders on the skid resistance of the UTWC is significant. The SinoTPS modified asphalt mixture can maintain high texture roughness before and after abrasion, providing excellent and durable skid resistance. The influence of the addition of a warm mixing additive on the skid resistance of UTWC is not significant, and changes in microtexture mainly reflect its impact on antiskid performance. The decay curve of three modified asphalt binders of the skid resistance of the UTWC can be well fitted into an exponential function. The conclusion will play an essential role in selecting the asphalt binder in a UTWC to improve the antiskid performance.

\section{Introduction}

Road safety issues are still a major social issue worldwide, and road safety accidents significantly threaten people's lives every year worldwide [1]. The better the skid resistance of the road is, the fewer road safety accidents that will occur. Particularly on highways, the skid resistance of pavement has become one of the critical factors affecting traffic accidents [2-4].

The road engineering workers always favor the research on the skid resistance of pavement. It is better to pay attention to skid resistance monitoring and improving its measurement accuracy to ensure road safety [5]. The mixture of different coarse aggregate can improve antiwear performance [6]. Torbruegge and Wies [7] explored the correlation between the road surface texture and the wet sliding resistance by introducing the parameter set of selfaffine surfaces. Kane et al. [8] found that a new aggregate hardness parameter can well show that the aggregate can retain the friction performance. Road safety is closely related to the antiskid performance of the pavement. The antiskid performance of the pavement must be improved from the root cause, and the reasons must be analyzed to improve road safety.

The application of asphalt concrete wearing course can increase the traffic safety of asphalt pavement [9]. Ultrathin wearing course (UTWC) is regarded as a preventive maintenance measure of Asphalt Pavement [10]. Experts and scholars pay attention to the skid resistance. The National Cooperative Highway Research Program (NCHRP) 
108 report stated that aggregate property, gradation type, asphalt content, and construction technology all affect the macrotexture of the pavement [11]. For example, the shape and wear resistance of aggregate have a significant impact on the skid resistance of the pavement [12]. Lin and Tongjing [13] showed that the influence of Fine Aggregate Angularity (FAA) value has a significant influence on the macrotexture of stone mastic asphalt (SMA) pavement. Wasilewska [14] found that the mixture with granite and basalt showed a higher friction coefficient by comparing the skid resistance of the SMA $(11 \mathrm{~mm})$ wearing course with different aggregates. Wang et al. [15] considered that the decrease of skid resistance property with time is caused by microstructure change. The volume parameters of the asphalt mixture also affect the skid resistance, and it needs to integrate multiple indicators to evaluate the skid resistance [16]. Hu et al. [17] show that the macrotexture of pavement is related to the friction coefficient and affects the skid resistance. A large number of studies by road researchers have shown that the factors affecting the road surface's antiskid performance mainly come from aggregates.

In addition, temperature, climate, humidity, and other environmental factors also affect the pavement's skid resistance $[18,19]$. El-Desouky [20] considered the fact that the change of temperature would affect the measurement of skid resistance. Muñoz [21] showed that the skid resistance of the Ultrathin Bonded Wearing Course decreased with the increase of temperature. The change of season also affects the skid resistance of the pavement, and the potential influence of various factors on the skid resistance is implied in the alternation of seasons [22]. The roughness of pavement reflects the skid resistance, and the change of average roughness is the result of the joint action of load and temperature [23]. The skid resistance of roads related to the dry and wet state of the road surface; the wet road has a significant impact on road traffic accidents [24]. The impact of the road service environment on antiskid performance is also significant.

As mentioned above, the research on the skid resistance of UTWC mainly focuses on the aggregate characteristics and environmental factors as temperature. Asphalt, as the binder of wearing course mixture, its performance characteristics, and adhesion with aggregate significantly affect the volume parameters of the mixture $[25,26]$. Hadiwardoyo et al. [27] believed that the skid resistance value is also influenced by asphalt characteristics, such as asphalt penetration index, softening point, and ductility. Kane et al. [28] also proposed that the aging of asphalt binders should be considered during the prediction of the antiskid performance of the road surface. Therefore, asphalt is also a significant potential factor affecting pavement skid resistance.

This study's objective is to explore the influence of different modified asphalt binders with warm mix additives on the skid resistance of UTWC and to reveal the attenuation law of skid resistance of UTWC. The Model Mobile Load Simulator 3 (MMLS3) was used to simulate repeated vehicle loading and abrasion. The Analysis of Range (ANOR) and Analysis of Variance (ANOVA) were used to verify the influence of asphalt binder on the antiskid performance of ultrathin wearing course. An exponential model was used for the analysis of the fitting equation coefficients.

\section{Technical Performance of Raw Materials}

2.1. Asphalt Binder. The materials used in this paper include three modified asphalt binders. The modifiers used were Styrene-Butadiene-Styrene (SBS), Acrylester Rubber (AR), and SinoTPS. Sasobit warm mix asphalt additive was used to prepare warm mix asphalt mixtures.

The neat asphalt binder used for UTWC is AH-70 petroleum asphalt. SBS-modified asphalt is the most commonly used in asphalt mixture [29, 30]. SinoTPS-modified asphalt as a high-viscosity modified asphalt is commonly used for comparison [31]. AR-modified asphalt is also concerned because of its economy and environmental protection [32, 33].

SBS is one of the polymers used as a modifier. The SBSmodified asphalt is made with $12 \%$ SBS and $88 \%$ AH-70 neat binder. It is prepared in the lab via a high shear mixer at 4000-5000 r/min and $180^{\circ} \mathrm{C}$ for 1 hour then at a constant temperature of $170^{\circ} \mathrm{C}$ for 2 hours. The SinoTPS is an asphalt binder modifier that can significantly improve the viscosity of asphalt binders. The modifier was designed and produced by a corporation in Shenzhen, China. The SinoTPS-modified asphalt included 16\% SinoTPS and 84\% AH-70 neat binder, and it is prepared in the lab via a high shear mixer at $8000 \mathrm{r} / \mathrm{min}$ and $170 \sim 180^{\circ} \mathrm{C}$ for 1.5 hours. AR-modified asphalt is composed of $20 \%$ rubber powder and $80 \% \mathrm{AH}-70$ neat asphalt at $1000 \mathrm{r} / \mathrm{min}$ and $180^{\circ} \mathrm{C}$ for 1 hour.

In the process of paving and compaction, the temperature of the UTWC asphalt mixture drops rapidly, which will cause the UTWC to be difficult to compact and will reduce the road performance. Warm mix cools more slowly than the hot mix since there is a smaller difference between the mix temperature and the surrounding air. The lower temperature means that the warm mix will have a reduced viscosity during construction. It will not resist the flow as much as hot mix, which means that better compaction is achievable at a lower compaction temperature. The application of warm mix asphalt pavements has a positive effect for saving $\mathrm{CO}_{2}$ emissions and prolonging the construction season [34].

Sasobit, a warm mix asphalt additive produced in South Africa, was used in the test. The use of the warm mix asphalt additive (sasobit) is simple in operation and can be stably dispersed in asphalt only by simple heating and asphalt mixing. It is not easily separated, has excellent workability, and is easy to use. Sasobit has solid particles with the appearance of white or light yellow, as shown in Figure 1. The primary technical indicators are shown in Table 1. For the warm mix asphalt additive product, the supplier's recommended dosage is 1.5\% 3\% of the quality of rubber asphalt binder. Sasobit was added into SBS-modified asphalt, SinoTPS high-viscosity modified asphalt, and AR-modified asphalt by a wet process.

According to the Standard Test Method of Asphalt and Asphalts Mixtures for Highway Engineering (JTG E20-2011), the test results of neat asphalt (AH-70) and 


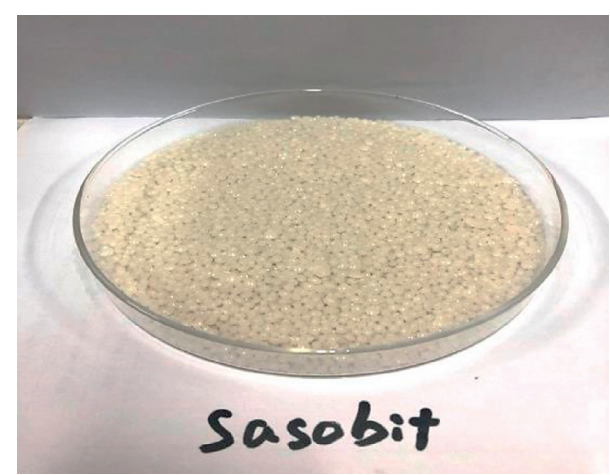

Figure 1: Sasobit powder.

TABLE 1: Test results of sasobit.

\begin{tabular}{lcc}
\hline Test item & Unit & Test results \\
\hline Drop melting point & ${ }^{\circ} \mathrm{C}$ & 105 \\
Flashpoint & ${ }^{\circ} \mathrm{C}$ & 290 \\
Density $\left(25^{\circ} \mathrm{C}\right)$ & $\mathrm{g} / \mathrm{cm}^{3}$ & 0.94 \\
Viscosity $\left(135^{\circ} \mathrm{C}\right)$ & $\mathrm{Pa} \cdot \mathrm{s}$ & 12 \\
Penetration $\left(65^{\circ} \mathrm{C}\right)$ & $0.1 \mathrm{~mm}$ & 5 \\
\hline
\end{tabular}

modified asphalt (SBS, AR, and SinoTPS) are shown in Table 2 and Tables 3-5. Technical properties of AH-70 neat asphalt and SBS modified asphalt met the requirements of Technical Specifications for Construction of Highway Asphalt Pavement (JTG E20-2004) in China. Technical properties of the SinoTPS-modified asphalt and AR-modified asphalt met the requirements of Technical Specifications for Maintenance of Highway Asphalt Pavement (JTG 5142-2019) in China.

2.2. Aggregate. Two types of aggregates were used in this study. The coarse aggregate and fine aggregates are diabase and limestone, respectively. Coarse and fine aggregate sizing is classified as follows: particles smaller than $2.36 \mathrm{~mm}$ are fine and above $2.36 \mathrm{~mm}$ are coarse. The nominal maximum size of the aggregate of SMA is $8 \mathrm{~mm}$ (SMA-8). The aggregates test according to the Specifications and Test Methods of Aggregate for Highway Engineering (JTG E422005), the test results of diabase coarse aggregates are shown in Table 6, and the test results of fine limestone aggregates are shown in Table 7.

2.3. Asphalt Mixtures. The SMA-8 with six different asphalt binders (three contains warm mix additive) were prepared in this paper. The asphalt mixture with SBS-modified asphalt named as SBS-SMA-8 (WSBS-SMA-8 was named with the addition of warm mix additive), the mixture with AR-modified asphalt was named as AR-SMA-8 (WAR-SMA-8 was named with the addition of warm mix additive), and the mixture with SinoTPS-modified asphalt was named as TPS-SMA-8 (WTPS-SMA-8 was named with added warm mix additive). The test result of different asphalt mixtures is shown in Table 8.

The gradation of SMA-8 is shown in Figure 2. Air voids and compaction temperature curve of warm asphalt mixture is shown in Figure 3. It is determined that the compaction temperature of warm SBS-modified asphalt mixture is $140^{\circ} \mathrm{C}$ (the hot mixing is $160^{\circ} \mathrm{C}$ ), warm mixing SinoTPS highviscosity modified asphalt mixture is $155^{\circ} \mathrm{C}$ (the hot mixing is $170^{\circ} \mathrm{C}$ ), and warm mixing AR-modified asphalt mixture is $160^{\circ} \mathrm{C}$ (the hot mixing is $170^{\circ} \mathrm{C}$ ). Asphalt mixture test slab production process contains mixture transfer and heat dissipation process. The compaction temperature of the asphalt mixture test slab is about $10^{\circ} \mathrm{C} \sim 15^{\circ} \mathrm{C}$ lower than the corresponding mixing temperature. The mixing temperature of the mixture with warm mixing SBS-modified asphalt is $150^{\circ} \mathrm{C} \sim 155^{\circ} \mathrm{C}$ (the hot mix is $170^{\circ} \mathrm{C} \sim 175^{\circ} \mathrm{C}$ ), the mixing temperature of the mixture with warm mixing SinoTPS high-viscosity modified asphalt is $165^{\circ} \mathrm{C} \sim 170^{\circ} \mathrm{C}$ (the hot mix is $180^{\circ} \mathrm{C} \sim 185^{\circ} \mathrm{C}$ ), and the mixing temperature of warm mixing AR-modified asphalt is $170^{\circ} \mathrm{C} \sim 175^{\circ} \mathrm{C}$ (the hot mix is $180^{\circ} \mathrm{C} \sim 185^{\circ} \mathrm{C}$ ) [35]. The size of the test slab is $300 \times 180 \times 100 \mathrm{~mm}$. Each test slab consists of three layers, a $20 \mathrm{~mm}$ top layer with SMA-8, a $40 \mathrm{~mm}$ middle layer with AC-13, and $40 \mathrm{~mm}$ bottom layer with AC-20. Figure 4 shows the structure of the test slabs.

\section{Test and Analysis Methods}

3.1. Test Methods. Figure 5 shows the test and work process design. The investigation of skid resistance was based on a scaled APT (Figure 6), and the MMLS3 is a piece of equipment employed in the test. The wheel load for the MMLS3 was set to $2.5 \mathrm{kN}$. The tire pressure was $0.75 \mathrm{MPa}$. 6,000 repetitions per hour. The test temperature was $25^{\circ} \mathrm{C}$. The skid resistance depends on the pavement surface texture (microtextural and macrotexture) [27, 36, 37]. The value of BPN provides a good approximation of the pavement microtexture size [38]. Sand Patch Method is one of the most effective techniques in macrotexture measurement [39]. In this paper, BPN and MTD are used to evaluate the skid resistance of UTWC. Before 100,000 loading cycles, BPN and MTD values were recorded at every 20,000 cycles. After 100,000 loading cycles, the data of BPN (MTD) was recorded at every 50,000 $(100,000)$ cycles. After one million cycles, the cyclic loading was terminated. The BPN tests were conducted, and the MTD values were measured via the Sand Patch test; both test methods were according to Field Test Methods of Highway Subgrade and Pavement (JTG 34502019) in China.

3.2. Analysis Methods. The skid resistance of asphalt pavement is related to the characteristics of aggregate, grading type, forming mode, the contact state of tire and pavement, and other factors. Different asphalt binders with warm mix additive on the antiskid performance and decay law of UTWC have been studied. It includes two factors: asphalt type and mix process, which meet the conditions of Analysis of Range (ANOR) and Analysis of Variance (ANOVA).

ANOR judges the main influencing factors by calculating the range of test results of various factors. $R_{j}$ is the range of factor $(j)$, as calculated by the following equation: 
TABLE 2: Technical properties of AH-70 binder.

\begin{tabular}{lccc}
\hline Test project & Technical requirement & Test result & Test methods \\
\hline Penetration $\left(25^{\circ} \mathrm{C}, 100 \mathrm{~g}, 5 \mathrm{~s}\right)(0.1 \mathrm{~mm})$ & $60-80$ & 69 & 48 \\
Softening point $(\mathrm{R} \& \mathrm{~B})\left({ }^{\circ} \mathrm{C}\right)$ & $\geq 46$ & 100 & $\mathrm{~T} 0606$ \\
Ductility $\left(15^{\circ} \mathrm{C}, 5 \mathrm{~cm} / \mathrm{min}\right)(\mathrm{cm})$ & $\geq 40$ & 314 & $\mathrm{~T} 0605$ \\
Flashpoint $\left({ }^{\circ} \mathrm{C}\right)$ & $\geq 260$ & 99.8 & $\mathrm{~T} 0611$ \\
Solubility $\%)$ & $\geq 99.5$ & 1.03 & $\mathrm{~T} 0607$ \\
Density $\left(15^{\circ} \mathrm{C}\right)\left(\mathrm{kg} / \mathrm{m}^{3}\right)$ & Measured record & 0.17 & $\mathrm{~T} \mathrm{0603}$ \\
\hline After thin-film oven test $(\mathrm{TFOT}) 163^{\circ} \mathrm{C}, 5 \mathrm{~h}$ & & 65.4 & $\mathrm{~T} 0609$ \\
Mass loss $(\%)$ & \pm 0.8 & 17 & $\mathrm{~T} \mathrm{0604}$ \\
Penetration ratio $(\%)$ & $\geq 61$ & $\mathrm{~T} \mathrm{0605}$ \\
Retained ductility $\left(5^{\circ} \mathrm{C}\right)(\mathrm{cm})$ & $\geq 15$ & & \\
\hline
\end{tabular}

TABLE 3: Technical properties of SBS-modified asphalt.

\begin{tabular}{|c|c|c|c|c|}
\hline \multirow{2}{*}{ Test project } & \multirow{2}{*}{ Technical requirement } & \multicolumn{2}{|c|}{ Test result } & \multirow{2}{*}{ Test methods } \\
\hline & & Hot mix & Warm mix & \\
\hline Penetration $\left(25^{\circ} \mathrm{C}, 100 \mathrm{~g}, 5 \mathrm{~s}\right)(0.1 \mathrm{~mm})$ & $60-80$ & 64 & 64.7 & T 0604 \\
\hline Softening point $(\mathrm{R} \& \mathrm{~B})\left({ }^{\circ} \mathrm{C}\right)$ & $\geq 60$ & 78 & 86.4 & T 0606 \\
\hline Ductility $\left(5^{\circ} \mathrm{C}, 5 \mathrm{~cm} / \mathrm{min}\right)(\mathrm{cm})$ & $\geq 30$ & 43.2 & 41.7 & T 0605 \\
\hline Kinematic viscosity $\left(135^{\circ} \mathrm{C}\right)$ & $\leq 3$ & 0.96 & 1.08 & T 0625 \\
\hline Flashpoint $\left({ }^{\circ} \mathrm{C}\right)$ & $\geq 230$ & 319 & 318 & T 0611 \\
\hline Elastic recovery (\%) & $\geq 60$ & 78 & 76.9 & T 0662 \\
\hline Toughness $(\mathrm{N} \cdot \mathrm{m})$ & $\geq 2.5$ & 2.75 & 2.7 & Т 0624 \\
\hline Storage stability $\left({ }^{\circ} \mathrm{C}\right)$ & $\leq 2.5$ & 1.7 & 1.5 & Т 0661 \\
\hline \multicolumn{5}{|c|}{ After thin-film oven test (TFOT) $163^{\circ} \mathrm{C}, 5 \mathrm{~h}$} \\
\hline Mass loss (\%) & \pm 1.0 & 0.20 & 0.18 & Т 0609 \\
\hline Penetration ratio $(\%)$ & $\geq 65$ & 68.1 & 69.3 & T 0604 \\
\hline Retained ductility $\left(5^{\circ} \mathrm{C}\right)(\mathrm{cm})$ & $\geq 20$ & 26 & 7 & T 0605 \\
\hline
\end{tabular}

TABLE 4: Technical properties of SinoTPS-modified asphalt.

\begin{tabular}{|c|c|c|c|c|}
\hline \multirow{2}{*}{ Test project } & \multirow{2}{*}{ Technical requirement } & \multicolumn{2}{|c|}{ Test result } & \multirow{2}{*}{ Test methods } \\
\hline & & Hot mix & Warm mix & \\
\hline Penetration $\left(25^{\circ} \mathrm{C}, 100 \mathrm{~g}, 5 \mathrm{~s}\right)(0.1 \mathrm{~mm})$ & $40-60$ & 48.9 & 42.3 & Т 0604 \\
\hline Softening point $(\mathrm{R} \& \mathrm{~B})\left({ }^{\circ} \mathrm{C}\right)$ & $\geq 75$ & 88.9 & 96.4 & Т 0606 \\
\hline Ductility $\left(5^{\circ} \mathrm{C}, 5 \mathrm{~cm} / \mathrm{min}\right)(\mathrm{cm})$ & $\geq 30$ & 43.7 & 42.4 & Т 0605 \\
\hline Kinematic viscosity $\left(135^{\circ} \mathrm{C}\right)$ & $\leq 3$ & 1.18 & 1.29 & Т 0625 \\
\hline Dynamic viscosity $\left(60^{\circ} \mathrm{C}\right)(\mathrm{Pa} \cdot \mathrm{s})$ & $\geq 20,000$ & 153718 & 160217 & Т 0620 \\
\hline Solubility (\%) & $\geq 99$ & 99.4 & 99.47 & Т 0607 \\
\hline Storage stability $\left({ }^{\circ} \mathrm{C}\right)$ & $\leq 2.5$ & 1.9 & 1.7 & Т 0661 \\
\hline Elastic recovery $(\%)$ & $\geq 85$ & 98.6 & 97.8 & Т 0662 \\
\hline \multicolumn{5}{|c|}{ After thin-film oven test (TFOT) $163^{\circ} \mathrm{C}, 5 \mathrm{~h}$} \\
\hline Mass loss (\%) & \pm 0.5 & 0.18 & 0.16 & T 0609 \\
\hline Penetration ratio $(\%)$ & $\geq 75$ & 81 & 76.5 & Т 0604 \\
\hline Retained ductility $\left(5^{\circ} \mathrm{C}\right)(\mathrm{cm})$ & $\geq 20$ & 29 & 30 & T 0605 \\
\hline
\end{tabular}

$$
R_{j}=\max \left\{K_{1 j}, K_{2 j}, \ldots, K_{i j}\right\}-\min \left\{K_{1 j}, K_{2 j}, \ldots, K_{i j}\right\},
$$

where $K_{i j}$ is the mean value of factor $(j)$ at one certain level [40, 41].

The influence of this factor's level change on the test index is significant while the $R j$ is large.

ANOVA decomposes the total variation (i.e., variance) of test indexes into the mutual variation of different factors to determine the importance of each factor in the total variation (just to judge the significance of the influence from various factors). In the ANOVA method, the sum of squares due to factor $\left(S S_{f}\right)$ is calculated by the following equations:

$$
S S_{\mathrm{f}}=\frac{\sum K_{\mathrm{f}}^{2}}{N}-\frac{\left(K_{i}\right)^{2}}{n},
$$

where $K_{\mathrm{f}}$ is the sums of test results of the factor, $K_{i}$ is the value at each level of the factor, $N$ is repeating the number of one factor, and $n$ is the number of tests. The variance value of factor $\left(V_{\mathrm{f}}\right)$ and the variance value of error $\left(V_{\mathrm{e}}\right)$ are calculated by the following equation: 
TABLE 5: Technical properties of AR-modified asphalt.

\begin{tabular}{|c|c|c|c|c|}
\hline \multirow{2}{*}{ Test project } & \multirow{2}{*}{ Technical requirement } & \multicolumn{2}{|c|}{ Test result } & \multirow{2}{*}{ Test methods } \\
\hline & & Hot mix & Warm mix & \\
\hline Penetration $\left(25^{\circ} \mathrm{C}, 100 \mathrm{~g}, 5 \mathrm{~s}\right)(0.1 \mathrm{~mm})$ & $30-60$ & 42.6 & 37.3 & T 0604 \\
\hline Softening point $(\mathrm{R} \& \mathrm{~B})\left({ }^{\circ} \mathrm{C}\right)$ & $\geq 60$ & 69 & 84.5 & T 0606 \\
\hline Ductility $\left(5^{\circ} \mathrm{C}, 5 \mathrm{~cm} / \mathrm{min}\right)(\mathrm{cm})$ & $\geq 20$ & 26 & 23 & T 0605 \\
\hline Rotational viscosity $\left(180^{\circ} \mathrm{C}\right)(\mathrm{Pa} \cdot \mathrm{s})$ & $2-4$ & 2.0 & 2.83 & T 0625 \\
\hline Storage stability $\left({ }^{\circ} \mathrm{C}\right)$ & $\leq 5$ & 2.3 & 2.1 & Т 0661 \\
\hline Elastic recovery $(\%)$ & $\geq 60$ & 78 & 79.3 & T 0662 \\
\hline \multicolumn{5}{|c|}{ After thin-film oven test (TFOT) $163^{\circ} \mathrm{C}, 5 \mathrm{~h}$} \\
\hline Mass loss $(\%)$ & \pm 0.5 & 0.23 & 0.2 & Т 0609 \\
\hline Penetration ratio (\%) & $\geq 65$ & 69.5 & 71.3 & Т 0604 \\
\hline Retained ductility $\left(5^{\circ} \mathrm{C}\right)(\mathrm{cm})$ & $\geq 5$ & 9 & 6 & T 0605 \\
\hline
\end{tabular}

TABLE 6: Test results of diabase coarse aggregate.

\begin{tabular}{|c|c|c|c|c|c|}
\hline \multirow{2}{*}{ Test project } & \multirow{2}{*}{ Technical requirement } & \multicolumn{3}{|c|}{ Test result } & \multirow{2}{*}{ Test method } \\
\hline & & $8.0-9.5 \mathrm{~mm}$ & $4.75-8.0 \mathrm{~mm}$ & $2.36-4.75 \mathrm{~mm}$ & \\
\hline Crushing value (\%) & $\leq 26$ & \multicolumn{2}{|c|}{12.9} & - & Т 0316 \\
\hline Polishing value & $\geq 42$ & \multicolumn{2}{|c|}{49.3} & - & Т 0321 \\
\hline Los Angeles abrasion value (\%) & $\leq 28$ & \multicolumn{2}{|c|}{14.1} & - & Т 0317 \\
\hline Apparent relative density $\left(\mathrm{g} / \mathrm{cm}^{3}\right)$ & $\geq 2.6$ & 2.949 & 2.959 & 2.942 & T 0321 \\
\hline Gross volume relative density $\left(\mathrm{g} / \mathrm{cm}^{3}\right)$ & Measure & 2.904 & 2.900 & 2.874 & Т 0308 \\
\hline Water absorption rate $(\%)$ & $\leq 2$ & 0.52 & 0.69 & 0.80 & Т 0308 \\
\hline
\end{tabular}

TABLe 7: Test results of fine limestone aggregate.

\begin{tabular}{lccc}
\hline Aggregate size & $\begin{array}{c}\text { Test } \\
\text { requirement }\end{array}$ & $\begin{array}{c}\text { Technical } \\
\text { result }\end{array}$ & $\begin{array}{c}\text { Test } \\
\text { method }\end{array}$ \\
\hline $\begin{array}{l}\text { Apparent relative } \\
\text { density }\end{array}$ & $\geq 2.50$ & 2.756 & T 0328 \\
$\begin{array}{l}\text { Firmness coefficient } \\
(\%)\end{array}$ & $\geq 12$ & 6.7 & T 0340 \\
$\begin{array}{l}\text { Methylene blue value } \\
\text { (g/kg) }\end{array}$ & $\leq 25$ & 6 & T 0349 \\
$\begin{array}{l}\text { Angularity (flow } \\
\text { time) (s) }\end{array}$ & $\geq 30$ & 62 & T 0345 \\
\hline
\end{tabular}

$$
\begin{aligned}
& V_{\mathrm{f}}=\frac{\mathrm{SS}_{\mathrm{f}}}{n-1}, \\
& V_{\mathrm{e}}=\frac{\mathrm{SS}_{\mathrm{e}}}{\mathrm{DOF}_{e}},
\end{aligned}
$$

where $\mathrm{SS}_{\mathrm{e}}$ is the sum of squares due to error, $(n-1)$ is the degree of freedom (DOF) of one factor, and $\mathrm{DOF}_{\mathrm{e}}$ is the number of errors' degree of freedom. Construct the following equations to calculate statistics $F_{\mathrm{f}}$.

$$
F_{\mathrm{f}}=\frac{V_{\mathrm{f}}}{V_{\mathrm{e}}} .
$$

For a given level of significance $\alpha, F_{a}$ can be obtained from the $F$ distribution table; if $F_{f}>F_{\alpha}$, the effect of this factor is significant [40-42].

An exponential model is used to fit the skid resistance deterioration of the UTWC using different asphalt binders. Some literatures pointed out that the skid resistance of asphalt pavements can be predicted by mathematical models $[4,43-45]$. The exponential model is

$$
Y=A+B \cdot \operatorname{EXP}(-k \cdot x)
$$

where $Y$ is the value of BPN or MTD of the UTWC under any number of loading cycles, $A$ is the terminal value of BPN or MTD, $B$ is the loss value of BPN or MTD, $A+B$ is the initial value of BPN or MTD, $k$ is the loss rate of BPN or MTD, and $x$ is the number of loading cycles.

\section{Results and Discussion}

4.1. BPN Test Results. The BPN test result of UTWC with modified asphalt under different loading repetitions is shown in Figure 7. It can be observed that the BPN value decreases with the increase of loading repetitions, while the attenuation rate also decreases. According to Technical Specifications for Maintenance of Highway Asphalt Pavement (JTG 5142-2019), if the BPN value is greater than 45, the pavement is considered to have satisfactory skid resistance.

The initial value, terminal value, and loss value of BPN are shown in Figure 8 . The initial value and terminal value of TPS-SMA are both at a high level compared with AR-SMA. The terminal value of TPS-SMA and SBS-SMA are very close, and they are $2.8 \%$ and $2.6 \%$ higher than those of ARSMA, respectively. The AR-SMA has the highest initial value but the lowest terminal value. The initial value of AR-SMA is $1.3 \%$ higher than TPS-SMA and 2.2\% higher than SBS-SMA. The order of the rate of BPN loss is SBS-SMA (35.0\%) $<$ TPSSMA $(35.3 \%)<$ AR-SMA (38.0\%). Both TPS-SMA and SBSSMA have better durability of skid resistance than AR-SMA. The addition of the warm mix additive reduces the initial 
TABLE 8: Test results of different asphalt mixtures.

\begin{tabular}{lcccccc}
\hline Type of mixture & $\begin{array}{c}\text { Porosity } \\
(\%)\end{array}$ & $\begin{array}{c}\text { VMA } \\
(\%)\end{array}$ & $\begin{array}{c}\text { Marshall stability } \\
(\mathrm{kN})\end{array}$ & $\begin{array}{c}\text { Freeze-thaw splitting tensile } \\
\text { strength ratio }(\%)\end{array}$ & $\begin{array}{c}\text { Dynamic stability } \\
(\text { times } / \mathrm{mm})\end{array}$ & $\begin{array}{c}\text { Mass loss } \\
(\%)\end{array}$ \\
\hline Technical & $3 \sim 4.5$ & $\geq 17$ & $\geq 7$ & $\geq 80$ & $\geq 3000$ \\
requirement & 3.76 & 18.16 & 8.83 & 89.56 & 7163 \\
SBS-SMA-8 & 3.92 & 18.22 & 8.74 & 87.64 & 8223 \\
WSBS-SMA-8 & 3.97 & 19.86 & 9.05 & 91.88 & 7062 \\
TPS-SMA-8 & 3.88 & 18.32 & 9.12 & 88.36 & 7852 \\
WTPS-SMA-8 & 3.85 & 20.13 & 8.45 & 87.41 & 8.67 \\
AR-SMA-8 & 3.84 & 19.84 & 8.82 & 83.09 & 5.62 \\
WAR-SMA-8 & & & & & 8.54 \\
\hline
\end{tabular}

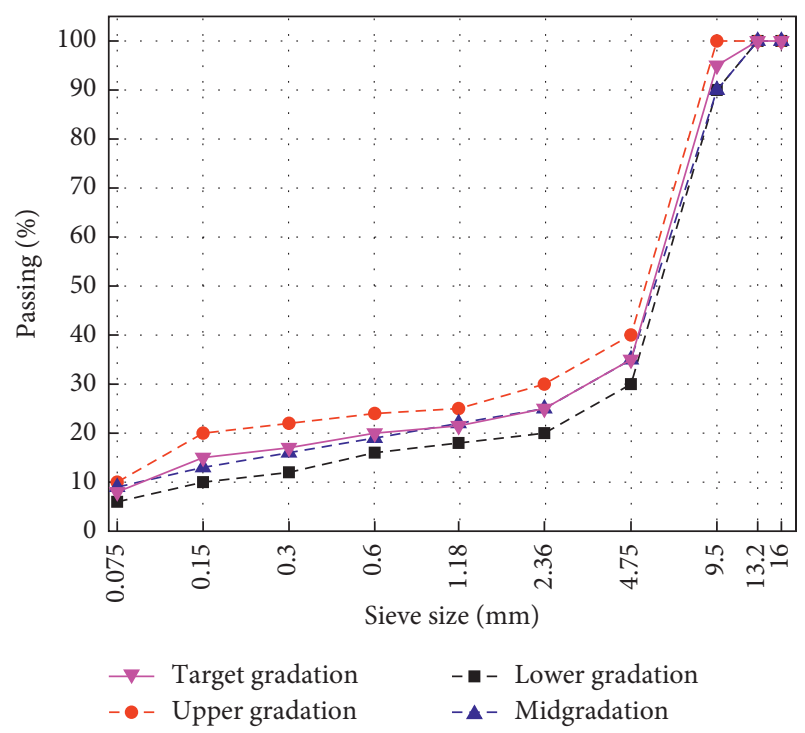

FIgURE 2: Aggregate gradation curve of SMA-8.

value $(0.9 \%)$ and terminal value $(2.5 \%)$, and it increases the average loss rate (2.2\%). However, warm mix asphalt reduces fuel consumption and cools more slowly than hot mix.

4.2. MTD Test Results. The MTD test result is shown in Figure 9. The attenuation process of MTD is roughly similar to $\mathrm{BPN}$, and the loss rate in the early stage of the test is much faster than in the later stage of the test. Combined with Figure 10, the MTD values of SBS-SMA and TPS-SMA are both higher than AR-SMA. The initial value of SBS-SMA is the highest, then the TPS-SMA, and the lowest is AR-SMA. Compared with ARSMA, the initial value of SBS-SMA and TPS-SMA is increased by $17.6 \%$ and $11.4 \%$, respectively; the terminal value of SBSSMA and TPS-SMA remains at a higher level than the ARSMA. The loss rate of AR-SMA is $34.2 \%$, the TPS-SMA (36.7\%) is $2.5 \%$ higher than AR-SMA, and the SBS-SMA (40.5\%) is $6.3 \%$ higher than AR-SMA. The initial value and terminal value of MTD decreased by $2.2 \%, 2.5 \%$, respectively, with the addition of warm mix additive, but it does not influence the loss rate. According to the Technical Specifications for Maintenance of Highway Asphalt Pavement (JTG 5142-2019), if the MTD of the UTWC is over $0.6 \mathrm{~mm}$, the pavement is considered satisfactory skid resistance.

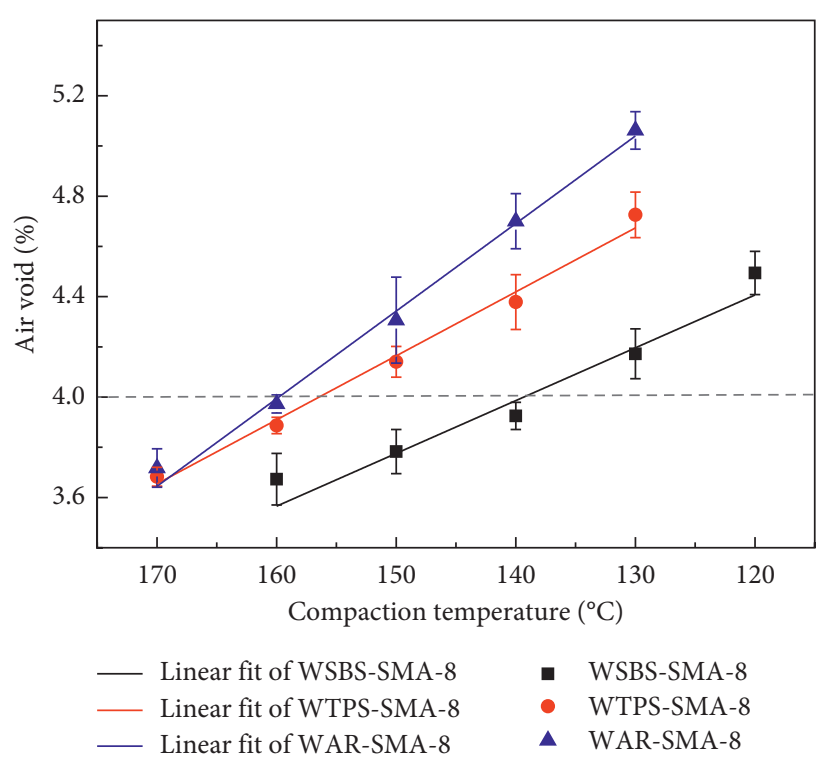

Figure 3: Air voids with the compaction temperature curve.

As shown in Figure 10, the initial value and terminal value of BPN of TPS-SMA are both at a high level compared with SBS-SMA and AR-SMA. The results show that the skid resistance performance of TPS-SMA is the most stable and prominent. As far as the indicators of the three modified asphalts are concerned, TPS modified asphalt has a higher viscosity, and elastic recovery value than that of SBSmodified asphalt and AR-modified asphalt. The test results of BPN and MTD show a gradual decrease in the attenuation rate. At the beginning of the test, the main body that bears the wheel wear is the asphalt film thickness on the aggregate surface. Then its skid resistance is mainly controlled by the aggregate characteristics after the surface asphalt has worn out [46]. A warm mix additive will affect the initial skid resistance and the terminal value in a minimal range and only influence the loss rate of BPN. This can be explained by the fact that the addition of warm mix additive will weaken the adhesion of asphalt-aggregate interface [47].

4.3. Analysis of Range. Analysis of the range method is used to compare the influence degree of different factors on skid resistance. Multiple indexes evaluate the skid resistance of UTWC, and skid resistance attenuation is a long and complicated process. In this paper, multiple indexes were 

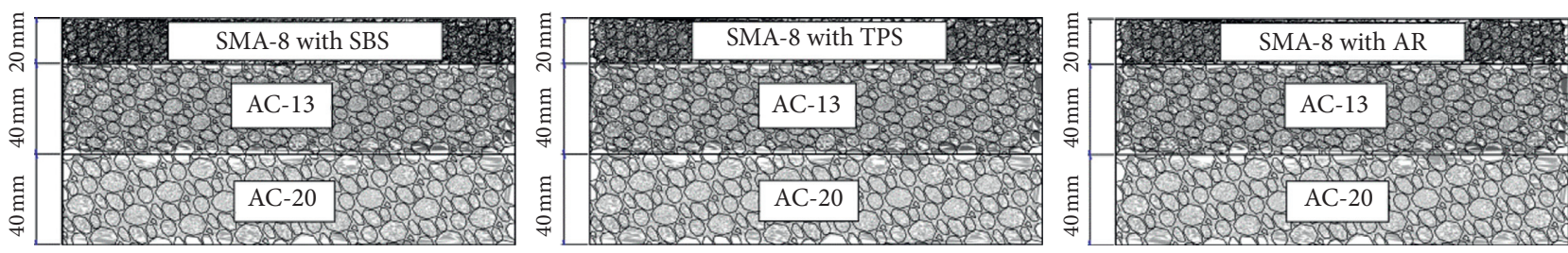

Figure 4: Structure of test slabs.

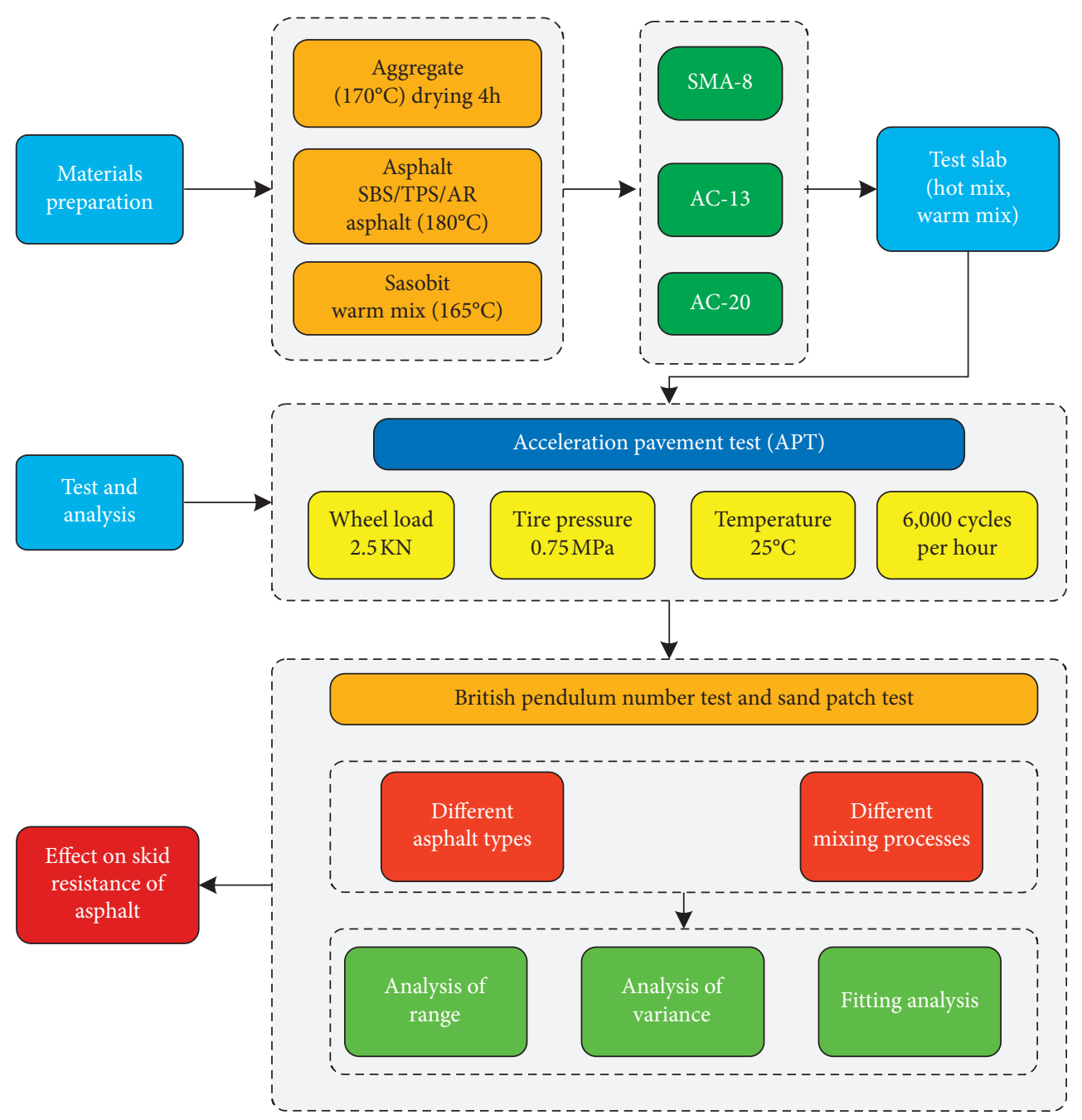

FIgURE 5: Flowchart of the test and work design.

used in ANOR. The results are shown in Table 9. For all evaluation indexes (BPN and MTD), the influence of asphalt type is higher than that of the mixing process (i.e., range one $>$ range two); the mixing process has little effect on the MTD data.

4.4. Analysis of Variance. For a given $a=0.05$, if the calculation result $F \geq F_{a}$, the factor has a significant impact on the test results; otherwise, it has no significant impact on the test results. As seen from Table 10, the influence of asphalt type and mixing process on the initial and terminal BPN values is significant. However, the interaction effect is not apparent. Asphalt binder type has a significant effect on the loss value of BPN. As for the initial value, terminal value, and loss value of MTD, only asphalt binder type has significant influence. It can be explained that the addition of warm mix additive (sasobit) mainly reduces the viscosity of asphalt binder but does not alter the volumetric properties of mixtures [48-50].

In summary, the influence of asphalt binder type on various indexes is significant. The mixing process (hot mix and warm mix) on the initial and terminal value of BPN is significant. 


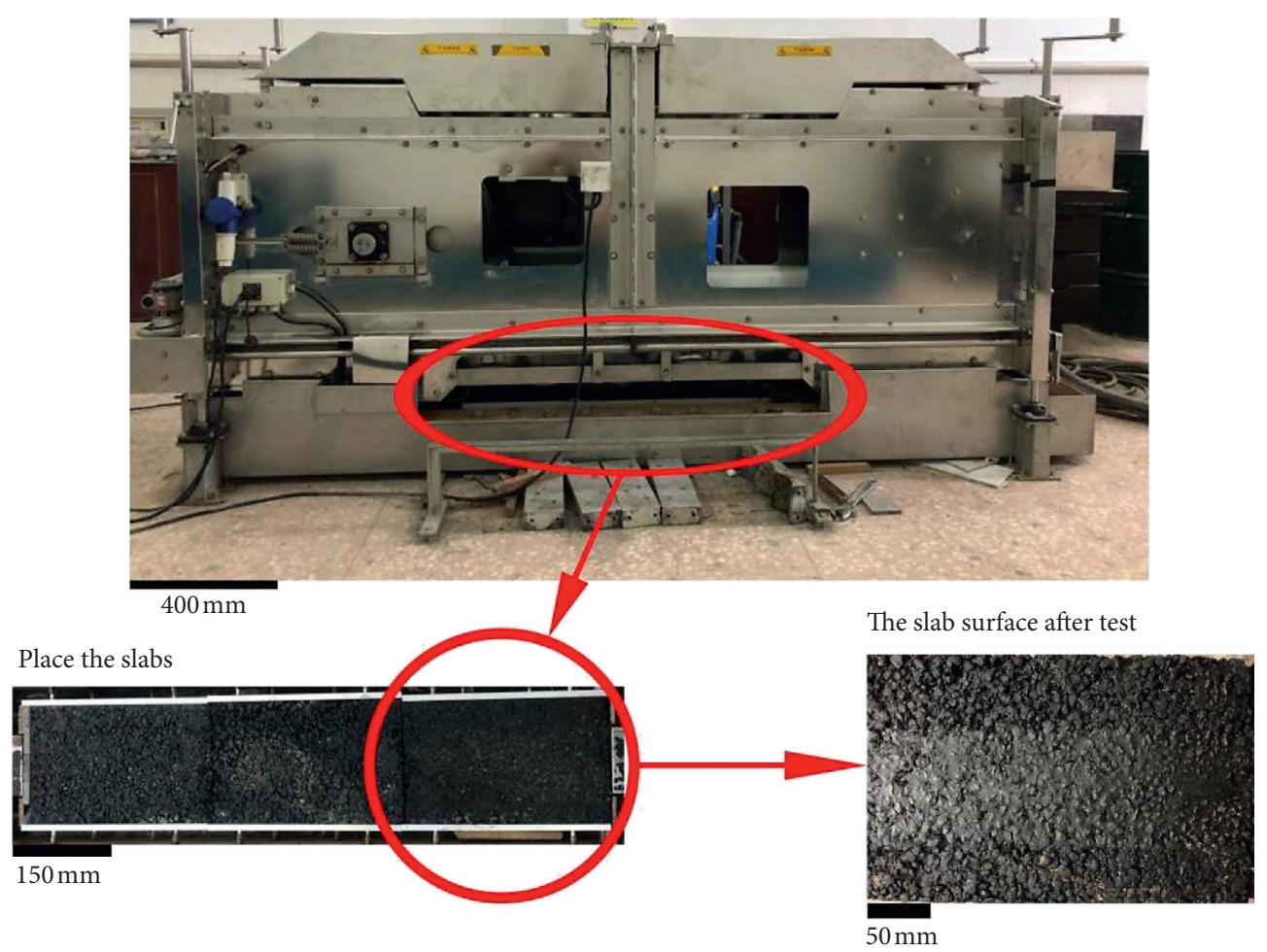

Figure 6: The Model Mobile Load Simulator (MMLS3) and the test slabs.

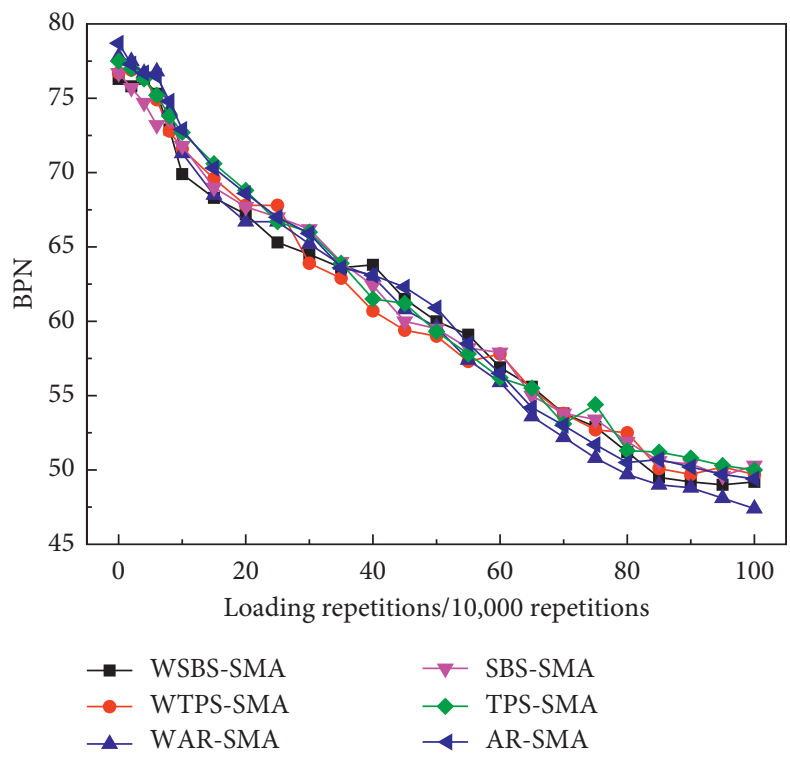

FIgURE 7: BPN test results.

4.5. Exponential Model Analysis. The BPN and MTD test results and exponential regression by formula 5 are shown in Figures 11 and 12, respectively. The antiskid performance (BPN and MTD) of UTWC decreases with repeated vehicle loading and abrasion, and the rate of decline gradually slows down.
Mathematical analysis shows that the value of $A$ is a prediction value for the terminal. The value of $B$ stands for the loss value of prediction, and $A+B$ is the initial value of prediction about the skid resistance. The predicted initial value in the model is close to the test result shown in Figure 11. However, there is a gap between the prediction of 


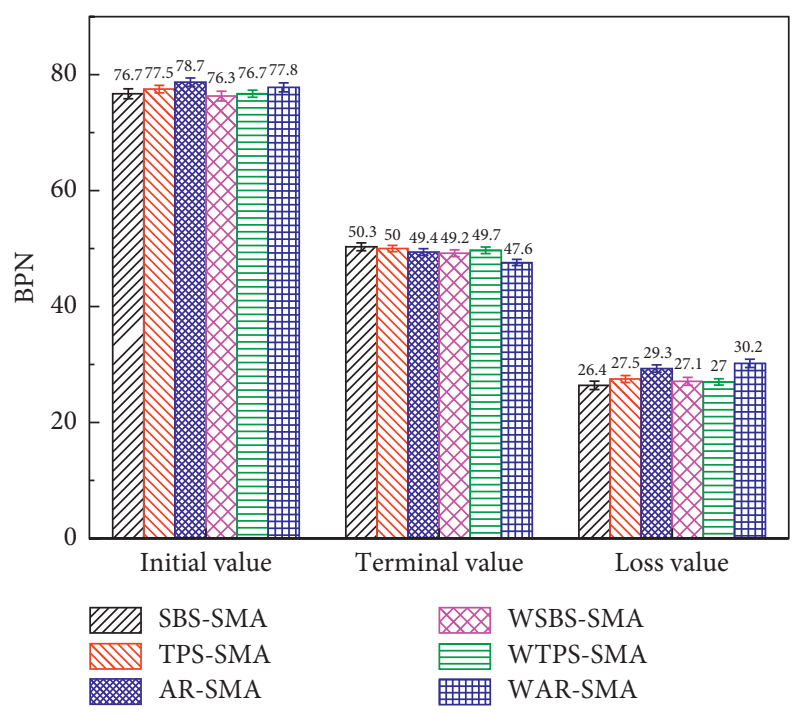

FigURE 8: BPN initial values, terminal values, and loss values of different mixtures.

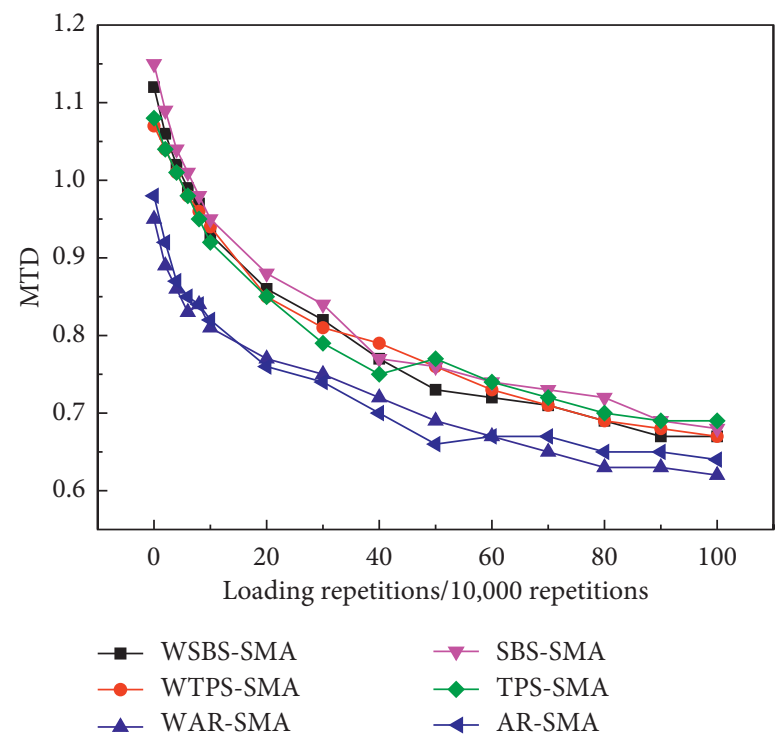

FIGURE 9: MTD test results.

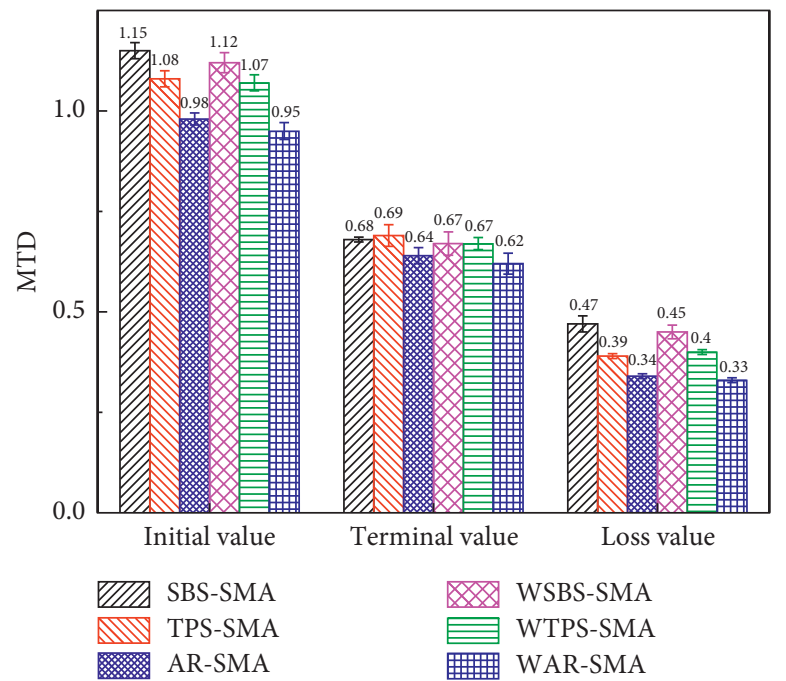

FigURE 10: MTD initial values, terminal values, and loss values of different mixtures. 
TABLE 9: Calculation results of ANOR.

\begin{tabular}{|c|c|c|c|c|c|c|c|}
\hline \multirow{2}{*}{ Factor } & & \multicolumn{3}{|c|}{ BPN } & \multicolumn{3}{|c|}{ MTD } \\
\hline & & Initial & Terminal & Loss & Initial & Terminal & Loss \\
\hline \multirow{3}{*}{ Modified asphalt type } & SBS & 76.5 & 49.75 & 26.75 & 1.135 & 0.675 & 0.46 \\
\hline & SinoTPS & 77.1 & 50.7 & 26.4 & 1.075 & 0.68 & 0.395 \\
\hline & AR & 78.25 & 48.5 & 29.75 & 0.965 & 0.63 & 0.335 \\
\hline Range one & & 1.75 & 2.2 & 3.35 & 0.17 & 0.05 & 0.125 \\
\hline \multirow{2}{*}{ Mixing process } & Hot mixing & 77.63 & 50.33 & 27.3 & 1.07 & 0.67 & 0.4 \\
\hline & Warm mixing & 76.93 & 48.97 & 27.97 & 1.05 & 0.65 & 0.39 \\
\hline Range two & & 0.7 & 1.36 & 0.67 & 0.02 & 0.02 & 0.01 \\
\hline
\end{tabular}

TABLe 10: Calculation results of ANOVA.

\begin{tabular}{|c|c|c|c|c|c|c|c|}
\hline \multirow{2}{*}{ Variation } & \multicolumn{3}{|c|}{$F(\mathrm{BPN})$} & \multicolumn{3}{|c|}{$F(\mathrm{MTD})$} & \multirow{2}{*}{$F_{a}$} \\
\hline & Initial & Terminal & Loss & Initial & Terminal & Loss & \\
\hline Asphalt type & 20.002 & 19.224 & 26.375 & 85.404 & 4.934 & 83.584 & 3.89 \\
\hline Mixing process & 9.925 & 22.118 & 2.593 & 4.691 & 1.355 & 0.713 & 4.75 \\
\hline Interaction effect & 0.443 & 0.566 & 0.123 & 0.383 & 0.054 & 1.248 & 3.89 \\
\hline
\end{tabular}



FIgURE 11: Fit function and test results of BPN.

terminal value and the test result. The loss of BPN is a longterm process, and it can still decay with the increase in loading repetitions. The prediction of the initial value and the terminal value in the fitting model is close to the test result shown in Figure 12.

\section{Conclusions}

This paper mainly studies the influence of different asphalt binders with warm mix additive on the skid resistance of UTWC. Based on the accelerating pavement test that used MMLS3, the following conclusions can be drawn:

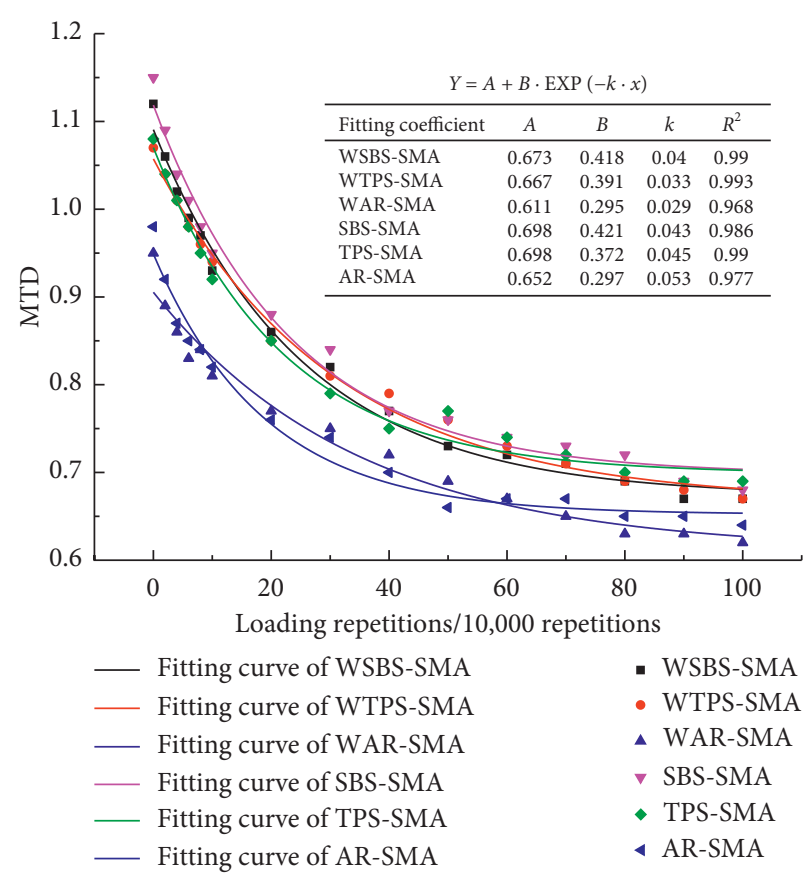

FIGURE 12: Fit function and test results of MTD.

(1) ANOR and ANOVA show that the influence of different modified asphalt binders on the skid resistance of the UTWC is significant. The results show that the TPS-SMA can maintain high texture roughness before and after abrasion, providing excellent and durable skid resistance.

(2) Compared with hot mix UTWC, there is some minor variation to the initial value and the terminal value with the addition of warm mixing additive. Changes in microtexture mainly reflect their impact on antiskid performance. 
(3) The antiskid performance (BPN and MTD) of UTWC decreases with repeated vehicle loading and abrasion, and the rate of decline of BPN and MTD gradually slows down. The decay curve of three modified asphalt binders of the skid resistance of the UTWC can be well fitted into an exponential function.

By analyzing the influence of different modified asphalt with warm mix additive on skid resistance, this study plays an essential role in selecting asphalt binder in a UTWC to improve the antiskid performance. Future studies can be done to focus on the influence of wet environment and different surface temperatures of the sample on the antislip performance of UTWC.

\section{Data Availability}

The data used to support the findings of this study are available from the corresponding author upon request.

\section{Conflicts of Interest}

The authors declare that there are no conflicts of interest regarding the publication of this paper.

\section{Acknowledgments}

This research was funded by the National Key R\&D Program of China (2018YFB1600100), National Natural Science Foundation of China (51608058), China Scholarship Council (CSC 201908430034), Education Department of Hunan Province (18B144), Open Fund of Key Laboratory of Special Environment Road Engineering of Hunan Province (Changsha University of Science \& Technology) (kfj190501), Postgraduate Research and Innovation Project in Changsha University of Science and Technology (CX2019SS04), and Key Research and Development Program of Hunan Province (2019SK2171).

\section{References}

[1] A. Ziakopoulos and G. Yannis, "A review of spatial approaches in road safety," Accident Analysis \& Prevention, vol. 135, Article ID 105323, 2020.

[2] J. N. Meegoda and S. Gao, "Evaluation of pavement skid resistance using high speed texture measurement," Journal of Traffic and Transportation Engineering, vol. 2, no. 6, pp. 382-390, 2015.

[3] R. B. Kogbara, E. A. Masad, E. Kassem, A. Scarpas, and K. Anupam, "A state-of-the-art review of parameters influencing measurement and modeling of skid resistance of asphalt pavements," Construction and Building Materials, vol. 114, pp. 602-617, 2016.

[4] Y. Miao, J. Li, X. Zheng, and L. Wang, "Field investigation of skid resistance degradation of asphalt pavement during early service," International Journal of Pavement Research and Technology, vol. 9, no. 4, pp. 313-320, 2016.

[5] P. Kotek and Z. Florková, "Comparison of the skid resistance at different asphalt pavement surfaces over time," Procedia Engineering, vol. 91, pp. 459-463, 2014.
[6] Y. Senga, A. Dony, J. Colin, S. Hamlat, and Y. Berthaud, "Study of the skid resistance of blends of coarse aggregates with different polish resistances," Construction and Building Materials, vol. 48, pp. 901-907, 2013.

[7] S. Torbruegge and B. Wies, "Characterization of pavement texture by means of height difference correlation and relation to wet skid resistance," Journal of Traffic and Transportation Engineering (English Edition), vol. 2, no. 2, pp. 59-67, 2015.

[8] M. Kane, I. Artamendi, and T. Scarpas, "Long-term skid resistance of asphalt surfacings: correlation between Wehner-Schulze friction values and the mineralogical composition of the aggregates," Wear, vol. 303, no. 1-2, pp. 235-243, 2013.

[9] A. Korochkin, "Impact of rigid pavements with the asphaltconcrete wearing course on road performance and traffic safety," Transportation Research Procedia, vol. 36, pp. 315319, 2018.

[10] M. Hu, L. Li, and F. Peng, "Laboratory investigation of OGFC5 porous asphalt ultra-thin wearing course," Construction and Building Materials, vol. 219, pp. 101-110, 2019.

[11] L. You, Z. You, and K. Yan, "Effect of anisotropic characteristics on the mechanical behavior of asphalt concrete overlay," Frontiers of Structural and Civil Engineering, vol. 13, no. 1, pp. 110-122, 2019.

[12] J. Hall et al., "Guide for pavement friction," Final Report for NCHRP Project, vol. 1, p. 43, 2009.

[13] C. Lin and W. Tongjing, "Effect of fine aggregate angularity on skid-resistance of asphalt pavement using accelerated pavement testing," Construction and Building Materials, vol. 168, pp. 41-46, 2018.

[14] M. Wasilewska, "Evaluation of skid resistance of wearing course made of stone mastic asphalt mixture in laboratory conditions," in IOP Conference Series: Materials Science and EngineeringIOP Publishing, Bristol, UK, 2017.

[15] D. Wang, P. Liu, H. Wang, A. Ueckermann, and M. Oeser, "Modeling and testing of road surface aggregate wearing behaviour," Construction and Building Materials, vol. 131, pp. 129-137, 2017.

[16] X. Zhou et al., "The influence of volume index of asphalt mixture on the skid resistance of asphalt pavement," Journal of Traffic and Transportation Engineering, vol. 17, no. 06, pp. 1-9, 2017.

[17] L. Hu, D. Yun, Z. Liu, S. Du, Z. Zhang, and Y. Bao, "Effect of three-dimensional macrotexture characteristics on dynamic frictional coefficient of asphalt pavement surface," Construction and Building Materials, vol. 126, pp. 720-729, 2016.

[18] C. Plati, M. Pomoni, and K. Georgouli, "Quantification of skid resistance seasonal variation in asphalt pavements," Journal of Traffic and Transportation Engineering, vol. 7, no. 2, 2019.

[19] M. Yu, Z. You, G. Wu, L. Kong, C. Liu, and J. Gao, "Measurement and modeling of skid resistance of asphalt pavement: a review," Construction and Building Materials, vol. 260, p. 119878, 2020.

[20] A. El-Desouky, "Investigating the effect of temperature variations on the measured airfield pavement skid resistance," Construction and Building Materials, vol. 161, pp. 649-653, 2018.

[21] J. F. Muñoz, C. Balachandran, Y. Yao et al., "Forensic investigation of the cause(s) of slippery ultra-thin bonded wearing course of an asphalt pavement: influence of binder content," International Journal of Pavement Engineering, vol. 19, no. 7, pp. 593-600, 2016.

[22] W. van Bijsterveld and M. A. del Val, "Towards quantification of seasonal variations in skid resistance measurements," Road 
Materials and Pavement Design, vol. 17, no. 2, pp. 477-486, 2015.

[23] M. Ech, S. Yotte, S. Morel, D. Breysse, and B. Pouteau, "Qualification of wearing course material surface evolution after durability test," Construction and Building Materials, vol. 35, pp. 313-320, 2012.

[24] T. F. Fwa, "Skid resistance determination for pavement management and wet-weather road safety," International Journal of Transportation Science and Technology, vol. 6, no. 3, pp. 217-227, 2017.

[25] L. You, K. Yan, T. Shi, J. Man, and N. Liu, "Analytical solution for the effect of anisotropic layers/interlayers on an elastic multi-layered medium subjected to moving load," International Journal of Solids and Structures, vol. 172-173, pp. 10-20, 2019.

[26] H. Liu, X. Yang, L. Jiang, S. Lv, T. Huang, and Y. Yang, "Fatigue-creep damage interaction model of asphalt mixture under the semi-sine cycle loading," Construction and Building Materials, vol. 251, Article ID 119070, 2020.

[27] S. P. Hadiwardoyo, E. S. Sinaga, and H. Fikri, "The influence of Buton asphalt additive on skid resistance based on penetration index and temperature," Construction and Building Materials, vol. 42, pp. 5-10, 2013.

[28] M. Kane, D. Zhao, M.-T. Do, E. Chailleux, and F. De-Lalarrard, "Exploring the ageing effect of binder on skid resistance evolution of asphalt pavement," Road Materials and Pavement Design, vol. 11, no. sup1, pp. 543-557, 2010.

[29] B. V. Kök, M. Yılmaz, and M. Akpolat, "Evaluation of the conventional and rheological properties of SBS + Sasobit modified binder," Construction and Building Materials, vol. 63, pp. 174-179, 2014.

[30] J. Liu, K. Yan, W. Liu, and X. Zhao, "Partially replacing Styrene-butadiene-styrene (SBS) with other asphalt binder modifier: feasibility study," Construction and Building Materials, vol. 249, 2020.

[31] Y. Luo, K. Zhang, P. Li, J. Yang, and X. Xie, "Performance evaluation of stone mastic asphalt mixture with different high viscosity modified asphalt based on laboratory tests," Construction and Building Materials, vol. 225, pp. 214-222, 2019.

[32] J. Gong, Y. Liu, Q. Wang et al., "Performance evaluation of warm mix asphalt additive modified epoxy asphalt rubbers," Construction and Building Materials, vol. 204, pp. 288-295, 2019.

[33] L. G. Picado-Santos, S. D. Capitão, and J. M. C. Neves, "Crumb rubber asphalt mixtures: a literature review," Construction and Building Materials, vol. 247, 2020.

[34] C. Raab, I. Camargo, and M. N. Partl, "Ageing and performance of warm mix asphalt pavements," Journal of Traffic and Transportation Engineering (English Edition), vol. 4, no. 4, pp. 388-394, 2017.

[35] G. Cheraghian, A. Cannone Falchetto, Z. You et al., "Warm mix asphalt technology: an up to date review," Journal of Cleaner Production, vol. 268, p. 122128, 2020.

[36] D. Woodward, P. Millar, C. Lantieri, C. Sangiorgi, and V. Vignali, "The wear of stone mastic asphalt due to slow speed high stress simulated laboratory trafficking," Construction and Building Materials, vol. 110, pp. 270-277, 2016.

[37] P. Georgiou and A. Loizos, "A laboratory compaction approach to characterize asphalt pavement surface friction performance," Wear, vol. 311, no. 1-2, pp. 114-122, 2014.

[38] O. K. Panagouli and A. G. Kokkalis, "Skid resistance and fractal structure of pavement surface," Chaos, Solitons \& Fractals, vol. 9, no. 3, pp. 493-505, 1998.
[39] N. Zuniga-Garcia and J. A. Prozzi, "High-definition field texture measurements for predicting pavement friction," Transportation Research Record: Journal of the Transportation Research Board, vol. 2673, no. 1, pp. 246-260, 2019.

[40] Y. Luo, Z. Zhang, and K. Zhang, "Sensitivity analysis of factors influencing shear stress of asphalt pavement under high temperature," Journal of Wuhan University (Engineering Edition), vol. 51, no. 10, pp. 895-900, 2018.

[41] P. Chen and B. Xu, "Reliability analysis of slope stability based on factor sensitivity," China Journal of Highway and Transport, vol. 25, no. 04, pp. 42-48, 2012.

[42] A. H. Bademlioglu, A. S. Canbolat, N. Yamankaradeniz, and O. Kaynakli, "Investigation of parameters affecting organic rankine cycle efficiency by using Taguchi and ANOVA methods," Applied Thermal Engineering, vol. 145, pp. 221-228, 2018.

[43] F. G. Praticò, R. Vaiana, and T. Iuele, "Macrotexture modeling and experimental validation for pavement surface treatments," Construction and Building Materials, vol. 95, pp. 658-666, 2015.

[44] X. Huang and B. Zheng, "Research status and prospect of asphalt pavement anti-skid performance," China Journal of Highway and Transport, vol. 32, no. 4, pp. 32-49, 2019.

[45] E. Kassem, A. Awed, E. A. Masad, and D. N. Little, "Development of predictive model for skid loss of asphalt pavements," Transportation Research Record: Journal of the Transportation Research Board, vol. 2372, no. 1, pp. 83-96, 2013.

[46] M.-T. Do, Z. Tang, M. Kane, and F. de Larrard, "Pavement polishing-development of a dedicated laboratory test and its correlation with road results," Wear, vol. 263, no. 1-6, pp. 36-42, 2007.

[47] J. Ji et al., "Effect of water and warm mixture on the adhesion of asphalt aggregate interface," China Journal of Highway and Transport, vol. 28, no. 07, pp. 25-30, 2015.

[48] R. Pereira, A. Almeida-Costa, C. Duarte, and A. Benta, "Warm mix asphalt: chemical additives' effects on bitumen properties and limestone aggregates mixture compactibility," International Journal of Pavement Research and Technology, vol. 11, no. 3, pp. 285-299, 2018.

[49] D. Ge, K. Yan, L. You, and Z. Wang, "Modification mechanism of asphalt modified with Sasobit and Polyphosphoric acid (PPA)," Construction and Building Materials, vol. 143, pp. 419-428, 2017.

[50] A. Jamshidi, M. O. Hamzah, and Z. You, "Performance of warm mix asphalt containing sasobit: state-of-the-art," Construction and Building Materials, vol. 38, pp. 530-553, 2013. 